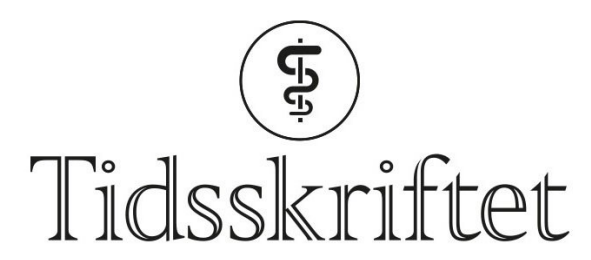

DEN NORSKE LEGEFORENING

\title{
Laparoskopisk reseksjon av ventrikkelcancer ved Oslo universitetssykehus, Ullevål 2015-18
}

ORIGINALARTIKKEL

TOM MALA

E-post: tommenmala@gmail.com Seksjon for øvre gastrokirurgi Avdeling for gastro- og barnekirurgi Oslo universitetssykehus, Ullevål Han har bidratt i analyse, tolkning, revisjon og godkjenning av manus. Tom Mala er dr.med., spesialist i gastroenterologisk kirurgi og overlege. Forfatter har fylt ut ICMJE-skjemaet og oppgir ingen interessekonflikter.

\section{HANS-OLAF JOHANNESSEN}

Seksjon før øvre gastrokirurgi Avdeling for gastro- og barnekirurgi Oslo universitetssykehus, Ullevål

Han har bidratt i analyse, tolkning, revisjon og godkjenning av manus.

Hans-Olaf Johannessen er dr.med., spesialist i gastroenterologisk kirurgi, overlege og seksjonsleder/fagansvarlig.

Forfatter har fylt ut ICMJE-skjemaet og oppgir ingen interessekonflikter.

\section{DAG FØRLAND}

Avdeling for gastro- og barnekirurgi

Oslo universitetssykehus, Ullevål

Han har bidratt i analyse, tolkning, revisjon og godkjenning av manus.

Dag Førland er ph.d., spesialist i gastroenterologisk kirurgi og overlege.

Forfatter har fylt ut ICMJE-skjemaet og oppgir ingen interessekonflikter.

\section{THOR HARALD JACOBSEN}

Avdeling for gastro- og barnekirurgi

Oslo universitetssykehus, Ullevål

Han har bidratt i analyse, tolkning, revisjon og godkjenning av manus.

Thor Harald Jacobsen er spesialist i gastroenterologisk kirurgi og overlege.

Forfatter har fylt ut ICMJE-skjemaet og oppgir ingen interessekonflikter

\section{EGIL JOHNSON}

Avdeling for gastro- og barnekirurgi

Oslo universitetssykehus, Ullevål

Og

Institutt for klinisk medisin

Universitetet i Oslo

Han har bidratt i analyse, tolkning, revisjon og godkjenning av manus. 
Egil Johnson er dr.med., spesialist i gastroenterologisk kirurgi, professor og overlege. Han er forskningsgruppeleder for oesophagus og ventrikkelsykdommer.

Forfatter har fylt ut ICMJE-skjemaet og oppgir ingen interessekonflikter

\section{BAKGRUNN}

Vi ønsket å evaluere våre erfaringer med laparoskopi ved kurativ reseksjon av ventrikkelcancer.

\section{MATERIALE OG METODE}

Alle pasienter med ventrikkelcancer operert med kurativ intensjon, uansett tilgang, i perioden 1.5.2015-28.2.2018 ved Oslo universitetssykehus, Ullevål, ble inkludert. Pasientforløp og onkologiske resultater ble registrert fortløpende og retrospektivt analysert.

\section{RESULTATER}

Totalt 93 pasienter ble operert. Av disse var 48 kvinner. Median alder var 73 (32-89) år, 16 pasienter var 80 år eller eldre. Operasjonstiden var 265 (125-644) minutter. Syv pasienter ble laparotomert, én var planlagt og seks ble konvertert til åpen kirurgi. Standardisert lymfeknutedisseksjon ble utført hos 88 pasienter. Komplikasjoner ble registrert hos 48 pasienter, hvorav 11 var alvorlige. Seks pasienter hadde anastomoselekkasje. Tre døde innen 30 dager/under sykehusoppholdet. Postoperativ liggetid var 12 (5-78) døgn. Totalt 86 pasienter ble radikalt operert, fem hadde tumorinfiltrasjon i reseksjonsrender og to hadde usikker reseksjonsstatus. Median antall lymfeknuter identifisert var 18 (o-53). Tumor var lokalavansert hos 56 pasienter.

\section{FORTOLKNING}

Laparoskopisk ventrikkelreseksjon med standardisert lymfeknutedisseksjon kan utføres hos de fleste pasienter med ventrikkelcancer som opereres med kurativ hensikt. Metoden er blitt standard behandling ved vår avdeling.

Insidensen av ventrikkelcancer i Norge har falt betydelig for begge kjønn de siste 6o årene, fra å være den hyppigste kreftformen i gastrointestinalkanalen til å være den fjerde hyppigste. I 2016 fikk 442 pasienter diagnosen ventrikkelcancer i Norge (1). Adenokarsinom er vanligst. Anslagsvis 30-40 \% av pasientene gjennomgår kirurgi med kurativ hensikt (2,3). Lokalavansert eller metastaserende sykdom er de vanligste årsakene til at kurativ kirurgi ikke kan gjennomføres. Enkelte pasienter kan ikke opereres på grunn av høy alder eller medisinske kontraindikasjoner. Den kirurgiske behandlingen er i stor grad sentralisert til regionssentre i Norge.

I henhold til nasjonale retningslinjer anbefales kjemoterapi før og etter kirurgi med kurativ hensikt til pasienter yngre enn 75 år, ellers ved individuell vurdering (4). Vanligvis utføres subtotal eller total ventrikkelreseksjon (gastrektomi), hovedsakelig avhengig av tumors lokalisasjon og utbredelse (fig 1, fig 2). Samtidig og standardisert disseksjon av spesifiserte lymfeknutestasjoner er innført som rutine ved de fleste sentre. Omfanget av lymfeknutedisseksjonen klassifiseres som D1 om den foregår nær ventrikkelen, eller som D2 om den innebærer mer omfattende disseksjon av lymfeknutestasjoner i relasjon til ventrikkelen (5). D2-disseksjonen synes å bedre kreftrelatert overlevelse sammenlignet med mindre omfattende disseksjon av lymfeknutestasjoner (4). 

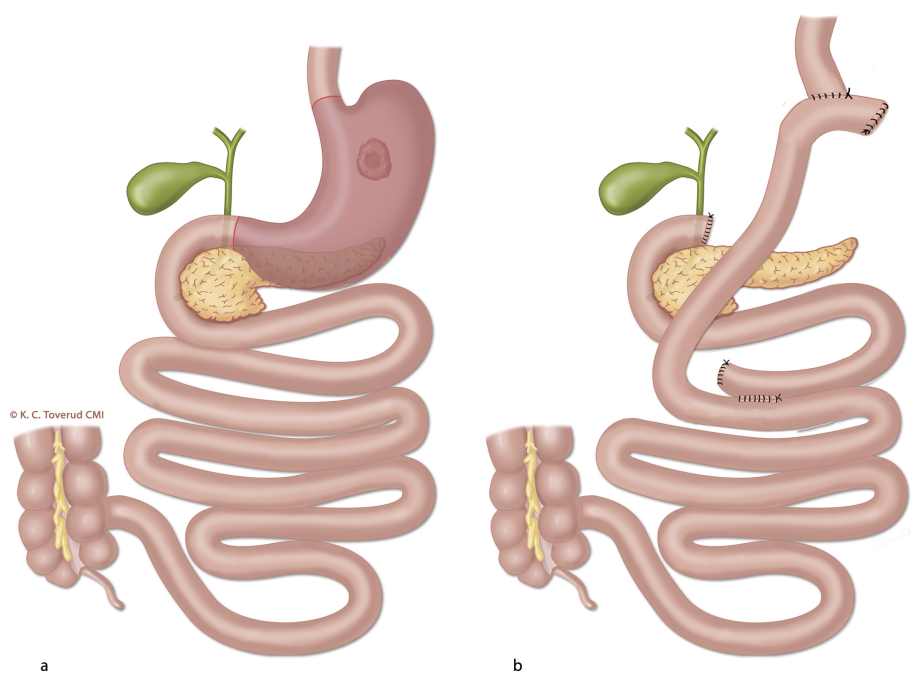

Figur 1 Tumor i proksimale del av ventrikkelen (a) og rekonstruksjon etter total gastrektomi (b).
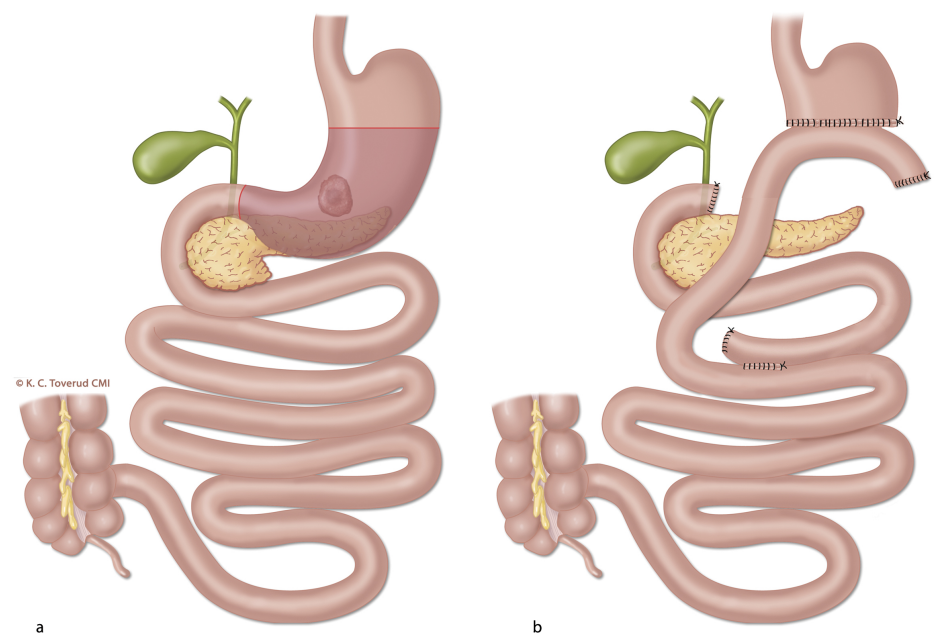

Figur 2 Tumor i distale del av ventrikkelen (a) og rekonstruksjon etter subtotal gastrektomi (b).

Ved reseksjon av ventrikkelcancer benyttes laparoskopi ved flere sentre i Norge og internasjonalt. Sikkerhet og onkologiske kortidsresultater ved laparoskopisk tilgang synes sammenlignbare med åpen kirurgi (6-8). Samtidig bruk av prinsipper for hurtig pasientforløp kan gi fordeler som kortere liggetid og rekonvalesens, muligens også reduserte kostnader, uten større risiko for komplikasjoner (9).

Samlet nedslagsfelt for spesialisthelsetjenester i Helse $\emptyset \emptyset r-\emptyset$ st er ca. 2,9 millioner mennesker. Omkring 50 pasienter per år fra helseregionen anses som kandidater for kirurgisk behandling av ventrikkelcancer med kurativ hensikt. I Helse Sør- st er denne behandlingen sentralisert til Akershus universitetssykehus og Oslo universitetssykehus, Ullevål. Laparoskopisk reseksjon av ventrikkelcancer ble innført ved Oslo universitetssykehus, Ullevål i 2015. Som del av arbeidet med kvalitetssikring og forbedringstiltak ønsket vi å evaluere våre tidlige erfaringer med bruk av denne metoden. Spesielt ønsket vi å vurdere komplikasjoner, pasientforløpet etter kirurgi og om tumor ble fjernet radikalt.

\section{Materiale og metode}

Alle pasienter som ble operert med kurativ intensjon for malign sykdom i magesekken ved Oslo universitetssykehus, Ullevål i perioden 1.5.2015-28.2.2018 ble inkludert i studien. Både pasienter operert med åpen tilgang og laparoskopisk tilgang ble inkludert. Alle pasientene ble vurdert for laparoskopisk tilgang. Vi inkluderte ikke pasienter operert i samme periode med torakolaparoskopisk oesophagus- og ventrikkelreseksjon for cancer ved gastroøsofageal overgang, da dette defineres som oesophaguscancer (10). 
Pasientkarakteristika, komplikasjoner, liggetid i sykehus, tumorkarakteristika og bruk av kjemoterapi ble registrert fortløpende i et kvalitetsregister ved avdelingen godkjent av personvernombudet, og ble retrospektiv analysert. Manglende data ble innhentet fra pasientjournal. Pasientene ga skriftlig samtykke til bruk av journalopplysninger. Undersøkelsen ble vurdert som en kvalitetssikringsstudie av Regional etisk komité for Helse Sør-Øst.

Utredning før kirurgi ble gjort i henhold til nasjonale retningslinjer og besto rutinemessig av gastroskopi med biopsi og CT-undersøkelse av abdomen og thorax. Det ble også gjort CTventrikulografi hovedsakelig for å vurdere tumors utbredelse og relasjon til naboorganer. Ved usikkerhet om operabilitet gjennomgikk enkelte pasienter diagnostisk laparoskopi før start av kjemoterapi. Pasientene som fikk kjemoterapi før kirurgi ble operert $4-6$ uker etter at kjemoterapibehandlingen var avsluttet.

Laparoskopi har ved vår avdeling rutinemessig vært benyttet ved bukdelen av reseksjon av spiserørskreft siden november 2007. Lymfeknutedisseksjonen samsvarer her dels med den som utføres for ventrikkelcancer. Modifisert D2-reseksjon for ventrikkelcancer ble innført ved avdelingen juli 2011 ved laparotomi. Ved denne disseksjonen tar man med vev fra spesifiserte lymfeknutestasjoner i relasjon til sentrale arterier nær ventrikkelen. «Modifisert» D2-disseksjon innebærer at lymfeknuter i milthilus som inkluderes i en formell D2-disseksjon, ikke tas med. Splenektomi ble utført ved direkte tumorinnvekst i milten, ellers kun ved mistanke om metastatiske lymfeknuter i milthilus (5).

Gastrointestinalkanalen ble rekonstruert etter reseksjon ved bruk av en Roux-en-Ykonfigurasjon der tynntarm koples mot avsatt oesophagus eller ventrikkelrest.

Alvorlige komplikasjoner ble definert ut ifra grad i henhold til Clavien-Dindoklassifikasjonen: IIIb (komplikasjon med behov for intervensjon i generell anestesi), IV (livstruende komplikasjon med behov for opphold på intensivavdeling) eller V(død) (11). Anastomoselekkasje ble definert som lekkasje påvist ved kontrastundersøkelse, gastroskopi eller laparoskopi. For pasienter overflyttet til lokalsykehus etter operasjon ble opplysninger om liggetid og eventuelle komplikasjoner innhentet. Eventuelle komplikasjoner etter utskrivning fra sykehus ble registrert ved første postoperative kontroll ved Oslo universitetssykehus seks uker etter operasjonen.

Tumors lokale utbredelse ble klassifisert i henhold til 7. utgave for TNM-klassifiseringen (4). Det er anbefalt at antall lymfeknuter evaluert fra preparatene er 16 eller flere for adekvat stadieinndeling $(4,12)$.

Pasientene fikk epiduralkateter for postoperativ smertelindring og kunne som hovedregel drikke samme dag. De ble mobilisert samme eller påfølgende dag. Abdominalt dren ble som hovedregel fjernet tredje eller fjerde postoperative dag. Kontrastundersøkelse av øvre anastomose ble ikke benyttet rutinemessig, men på indikasjon.

\section{Resultater}

Pasientkarakteristika er angitt i tabell 1. Totalt 93 pasienter med median alder 73 (32-89) år og kroppsmasseindeks $24(14-37) \mathrm{kg} / \mathrm{m}^{2}$ ble inkludert i studien. Kjemoterapi før kirurgi ble gitt til 44 pasienter (47,3\%). 52 pasienter ble operert med total gastrektomi og 41 med subtotal gastrektomi. Operasjonstiden for pasientene operert med total gastrektomi var 284 (135-644) minutter, og 266 (145-469) minutter for pasientene operert med subtotal gastrektomi. Hos tre pasienter ble det gjort samtidig distal oesophagusreseksjon. For én pasient planla man laparotomi på grunn av tumors lokalisasjon og omfang, de øvrige ble operert med laparoskopi. Seks pasienter $(6,5 \%)$ ble konvertert fra laparoskopi til laparotomi på grunn av blødning, forhold ved tumor (innvekst $\mathrm{i}$ andre organ), anastomose eller adheranser. Syv fikk utført reseksjon av andre organer som colon, milt, ovarium og deler av diafragma. Estimert blodtap på $\geq 500 \mathrm{ml}$ ble registrert hos fem pasienter (5,4\%). 


\section{Tabell 1}

Pasientkarakteristika hos 93 pasienter operert med kurativ intensjon for ventrikkelcancer ved Oslo universitetssykehus, Ullevål i perioden 1.5.2015-28.2.2018. ASA = American Society of Anesthesiologists.

\begin{tabular}{|c|c|}
\hline Pasientkarakteristika & Antall (\%) \\
\hline Kvinner & $48(51,6)$ \\
\hline Alder $\geq 80$ år & $16(17,2)$ \\
\hline \multicolumn{2}{|l|}{ ASA-klasse } \\
\hline ASA 1 & $6(6,4)$ \\
\hline ASA 2 & $50(53,7)$ \\
\hline ASA 3 & $37(39,8)$ \\
\hline
\end{tabular}

D2-disseksjon ble utført hos 88 pasienter (94,6\%). Hos de resterende fem ble det ikke utført adekvat D2-disseksjon på grunn av alder, alder kombinert med kreft i tidlig stadium/dysplasi, leukemi med betydelig lokal og generell glandulopati, besværlig disseksjon med blødning og laparotomi, samt omfattende tumor der det ikke var indisert.

Komplikasjoner ble registrert hos 48 pasienter (51,6\%) (tab 2). 11 (11,8\%) av disse hadde alvorlige komplikasjoner. Seks pasienter $(6,5 \%)$ hadde anastomoselekkasje. To av pasientene med anastomoselekkasje var konvertert fra laparoskopi til laparotomi på grunn av omfattende tumorvekst med annen organreseksjon. Åtte pasienter (8,6\%) ble reoperert ( $\operatorname{tab} 2$ ). To av reoperasjonene var etter konvertering til laparotomi ved primæroperasjonen.

\section{Tabell 2}

Komplikasjoner hos 48 av 93 pasienter (51,6\%) etter reseksjon av ventrikkelcancer med kurativ intensjon ved Oslo universitetssykehus, Ullevål 1.5.2015-28.2.2018.11 pasienter (11,8\%) hadde alvorlige komplikasjoner. Pasientene kan være registrert med én eller flere komplikasjoner.

\begin{tabular}{|ll|}
\hline Type komplikasjoner & Antall pasienter \\
\hline Alvorlige komplikasjoner & \\
\hline Respirasjonsstans, intensivopphold & 1 \\
\hline Aspirasjon/respirasjonssvikt, intensivopphold & 1 \\
\hline Reoperasjoner & 8 \\
\hline Sårruptur & $3^{2}$ \\
\hline Diagnostisk laparoskopi (negativ) & 2 \\
\hline Reponering av herniert tynntarm gjennom diafragma & 1 \\
\hline Reseksjon av iskemisk tynntarmsegment & 1 \\
\hline Anleggelse av bøyleenterostomi for pancreasfistel til colon & 1 \\
\hline Død ${ }^{3}$ & 3 \\
\hline Andre komplikasjoner & \\
\hline Behov for pleuradrenasje & 17 \\
\hline Pneumoni & 12 \\
\hline Dysfagi med blokking & 7 \\
\hline Anastomoselekkasje & 6 \\
\hline Atrieflimmer & 4 \\
\hline Delir & 3 \\
\hline Drenering av intraabdominal abscess & 3 \\
\hline Behov for antibiotika uten sikkert fokus & 3 \\
\hline Reinnleggelse (magesmerter eller dysfagi) & 3 \\
\hline Lungeemboli & 3 \\
\hline Sårinfeksjon & 2 \\
\hline
\end{tabular}




\begin{tabular}{|lc|}
\hline Type komplikasjoner & Antall pasienter \\
\hline Urinveisinfeksjon & 2 \\
\hline Andre komplikasjoner & 5 \\
\hline
\end{tabular}

'Behov for intervensjon i generell anestesi, behov for behandling ved intensivavdeling, og/eller død

${ }^{2}$ En pasient med tynntarmsskade

${ }^{3}$ To av pasientene som døde, var blant de åtte som ble reoperert

Tre pasienter (3,2 \%) døde innen 30 dager eller i løpet av sykehusoppholdet, som også inkluderte perioden etter overflytting til lokalsykehus. Én pasient døde på grunn av multiorgansvikt og to på grunn av infeksjon, kardiovaskulære komplikasjoner og generell svekkelse. Pasientene som døde var omkring 80 år eller eldre. Ved første postoperative kontroll ble syv pasienter henvist til gastroskopi og blokking av øvre anastomose på grunn av dysfagi etter total gastrektomi ( $\operatorname{tab} 2$ ).

Totalt 74 pasienter (79,6\%) lå ett døgn eller kortere på postoperativ avdeling etter prosedyren, hvorav $19(20,4 \%)$ mindre enn ett døgn. Syv pasienter $(7,5 \%)$ hadde behov for opphold på intensivavdeling. Samlet postoperativ liggetid i sykehus var 12 (5-78) døgn inkludert opphold på sykehotell for 46 pasienter (49,4\%) i 3,5 (1-20) døgn. Ved utskrivning reiste 72 pasienter $(77,4 \%)$ hjem eller til rekonvalesens, og 19 (21\%) til lokalsykehus (liggetid inkludert).

Samlet ble 86 pasienter $(92,4 \%$ ) bedømt som radikalt operert. Hos fem pasienter ble det funnet tumorvev i reseksjonsrender ved mikroskopi, og hos to som var uten påvist tumorvev i reseksjonsrendene, kunne man ikke sikkert konkludere på grunn av diffust vekstmønster. Median antall lymfeknuter identifisert etter D2-disseksjon var 18 (o-53). Av de 88 pasientene som fikk gjort D2-disseksjon, ble det hos 53 pasienter $(60,2 \%)$ identifisert $\geq$ 16 lymfeknuter. Tumor var lokalavansert $\left(\mathrm{T}_{3}-\mathrm{T}_{4}\right)$ hos $56(60,2 \%)$ av pasientene. Totalt hadde 90 av pasientene adenokarsinom, to nevroendokrin tumor og én høygradig dysplasi.

\section{Diskusjon}

Vi har her presentert våre erfaringer med innføring av laparoskopisk D2-reseksjon av ventrikkelcancer med kurativ hensikt. De fleste pasientene kunne opereres med denne tilgangen, og få ble konvertert til åpen kirurgi. Resultatene gjenspeiler læringskurven ved introduksjon av en ny metode. Det er nødvendig med et visst et antall prosedyrer før kirurgen har adekvat erfaring med forhold som operasjonstid, kirurgisk teknikk, onkologisk resultat og risiko for komplikasjoner (13).

I denne studien inkluderte vi komplikasjoner registrert under sykehusoppholdet og til og med første kontroll seks uker etter inngrepet. Det kan ha medført en høyere andel komplikasjoner enn i studier som registrerer komplikasjonsforekomst kun i zo dager etter inngrepet. De vanligste komplikasjonene vi registrerte var pneumoni og pleuravæske med behov for drenasje. Vi har lav terskel for å drenere pleuravæske, som delvis skyldes en aktiv holdning til drenasje ved oesophagusreseksjoner der utvikling av pleuravæske er vanlig (14).

Våre funn av perioperativ morbiditet og mortalitet synes sammenlignbare med resultater etter åpen kirurgi ved tilsvarende sentre. I en norsk serie var zo dagers mortalitet/sykehusmortalitet og morbiditet etter åpen reseksjon henholdsvis 5,3\% og 57\%. Forekomsten av anastomoselekkasje verifisert ved CT og/eller laparotomi var $7 \%$ (15). I en nasjonal oversikt fra Nederland over 442 åpne og 442 laparoskopiske operasjoner var perioperativ morbiditet og mortalitet henholdsvis $38 \% \operatorname{mot} 37 \%$ og $5 \%$ mot $6 \%$. Varigheten av sykehusoppholdet var ti og åtte dager (8). Dette samsvarer med resultatene i en amerikansk studie av 859 pasienter med ventrikkelcancer (16).

I den samme studien var median antall lymfeknuter 17 og andelen med tumorinfiltrasjon $\mathrm{i}$ 
reseksjonsranden 9,4\%(16). Tilsvarende tall fra den nederlandske oversikten viste at median antall lymfeknuter etter åpen og laparoskopisk ventrikkelreseksjon var henholdsvis 18 og 21. Radikal reseksjon (reseksjonsrender fri for tumorvev ved mikroskopi) ble oppnådd hos henholdsvis $85 \%$ og $88 \%$ av pasientene (8). Dette samsvarer med våre resultater. I en tidligere norsk studie var median antall lymfeknuter etter åpen radikal D2reseksjon 11 (15).

Nærmere hver femte pasient i vårt materiale var 80 år eller eldre. Mindre invasiv tilgang kan kanskje gjøre terskelen lavere for å operere i eldre aldersgrupper, men disse pasientene er mer utsatt for komplikasjoner (17).

Vår erfaring er at laparoskopi gir meget god oversikt og tilgang ved utførelsen av lymfeknutedisseksjonen. Det gjelder også ved disseksjon opp mot og i hiatus i diafragma. Ifølge årsrapporten for 2016 fra Nasjonalt kvalitetsregister for kreft i spiserør og magesekk ble $62 \%$ av pasientene som var innrapportert til registeret, operert for kreft i magesekken med laparoskopisk tilgang. Bruken av laparoskopi varierte mellom helseregionene, med høyest andel i Helse Sør- $\emptyset$ st og lavest i Helse Vest (2). Ved vår avdeling ser vi at laparoskopisk reseksjon av cancer i gastroøsofageal overgang og spiserør gir betydelige synergieffekter, idet tilgang og lymfeknutedisseksjonen i buken i stor grad samsvarer.

Enkelte sentre benytter robotkirurgi i behandlingen av ventrikkelcancer $(18,19)$. Robotassistert kirurgi viderefører teknikkene ervervet ved laparoskopisk kirurgi, men gir også mulighet for stabil og operatørstyrt kameraføring, eliminering av tremor/uro og tredimensjonal visualisering og bedret ergonomi for operatøren. «Håndleddsfunksjonen» til instrumentene flyttes intrakorporalt, noe som kan lette suturering. Vi ønsker å videreutvikle vår teknikk og å prøve ut robotassistert ventrikkelreseksjon som rutinetilnærming til denne prosedyren.

Liggetiden i sykehus i denne studien reflekterer trolig dels pasientens høye alder og ernæringsmessige utfordringer den første tiden etter operasjon. Vi ser behov for å optimalisere protokoller for raskere mobilisering, smertelindring og rehabilitering i den postoperative fasen. Dette har vi i stor grad håndtert ved utstrakt bruk av pasienthotellet og oppfølging av klinisk ernæringsfysiolog. Videre håper vi i samarbeid med patologene å bedre høstingen av lymfeknuter fra preparatene, slik at vi for de fleste pasientene identifiserer 16 eller flere lymfeknuter, som anses nødvendig for adekvat stadieinndeling (16). Ved standardisert disseksjon varierte antallet identifiserte lymfeknuter mellom o og 53 . Forhold som håndtering av operasjonspreparatet og patologens tid til disposisjon er trolig av betydning for det endelige antall lymfeknuter som identifiseres.

Det er behov for styrket kunnskapsgrunnlag om nytteverdi og effekter på langtidsoverlevelse for flere av endringene gjort i den terapeutiske tilnærmingen til ventrikkelcancer de senere år. Dette gjelder både bruk av laparoskopi eller annen minimal invasiv tilgang som robotkirurgi, bruk av D2-disseksjon og bruk av perioperativ kjemoterapi (20-24). En pågående randomisert studie i Nederland der man evaluerer åpen versus laparoskopisk gastrektomi for kreft, vil trolig bidra i denne sammenhengen (Logicastudien) (25). Pasientserier fra Asia synes å dominere når det gjelder beskrivelser av erfaringer med laparoskopisk gastrektomi, men resultatene fra disse er ikke nødvendigvis overførbare til vestlige og europeiske forhold.

Svakheter ved vår analyse inkluderer mulighet for at enkelte mindre alvorlige komplikasjoner kan ha blitt oversett eller ikke registrert i journal. Erfaringene representerer observasjoner fra læringskurven for den enkelte kirurg, og det er grunn til å tro at resultatene kan bedres med økende erfaring. I denne studien hadde vi ingen kontrollgruppe eller langtidsresultater.

Ved reseksjon av ventrikkelcancer med kurativ hensikt anser vi i dag laparoskopisk gastrektomi med standardisert lymfeknutedisseksjon som rutinemetode ved vår avdeling. 
HOVEDBUDSKAP

Laparoskopisk tilgang ble benyttet hos de fleste pasienter operert for ventrikkelcancer med kurativ intensjon

Adekvat lymfeknutedisseksjon ble utført hos de fleste pasientene

Nær hver femte pasient var 80 år eller eldre

\section{LITTERATUR:}

1. Cancer in Norway 2016 - Cancer incidence, mortality, survival and prevalence in Norway. Oslo:

Kreftregisteret, 2017. https://www.kreftregisteret.no/globalassets/cancer-in-norway/2016/cin-2106.pdf (10.9.2018).

2. Årsrapport 2016 med resultater og forbedringstiltak fra Nasjonalt kvalitetsregister for kreft i spiserør og magesekk. Oslo: Kreftregisteret, 2017.

https://www.kreftregisteret.no/globalassets/publikasjoner-og-rapporter/arsrapporter/publisert-2017/a rsrapport-2016_spiseror-og-magesekkreft.pdf(10.9.2018).

3. Bringeland EA, Wasmuth $\mathrm{HH}$, Mjønes P et al. A population-based study on incidence rates, Lauren distribution, stage distribution, treatment, and long-term outcomes for gastric adenocarcinoma in Central Norway 2001-2011. Acta Oncol 2017; 56:39 - 45. [PubMed][CrossRef]

4. Nasjonalt handlingsprogram med retningslingslinjer for diagnostikk, behandling og oppfølging av kreft i magesekken (ventrikkelkreft) IS-2361. Oslo: Helsedirektoratet, 2018.

https://helsedirektoratet.no/Lists/Publikasjoner/Attachments/145o/IS-2643\%20Handlingsprogram\%20 magesekkreft.pdf(10.9.2018).

5. Allum WH, Blazeby JM, Griffin SM et al. Guidelines for the management of oesophageal and gastric cancer. Gut 2011; 60: 1449 - 72. [PubMed][CrossRef]

6. Shi Y, Xu X, Zhao Y et al. Short-term surgical outcomes of a randomized controlled trial comparing laparoscopic versus open gastrectomy with D2 lymph node dissection for advanced gastric cancer. Surg Endosc 2018; 32:2427-33. [PubMed][CrossRef]

7. Park YK, Yoon HM, Kim YW et al. Laparoscopy-assisted versus open D2 distal gastrectomy for advanced gastric cancer: Results from a randomized phase II multicenter clinical trial (COACT 1001). Ann Surg 2018; 267: 638 - 45. [PubMed][CrossRef]

8. Brenkman HJF, Gisbertz SS, Slaman AE et al. Postoperative outcomes of minimally invasive gastrectomy versus open gastrectomy during the early introduction of minimally invasive gastrectomy in the Netherlands: A population-based cohort study. Ann Surg 2017; 266: 831 - 8. [PubMed][CrossRef]

9. Li Z, Wang Q Li B et al. Influence of enhanced recovery after surgery programs on laparoscopyassisted gastrectomy for gastric cancer: a systematic review and meta-analysis of randomized control trials. World J Surg Oncol 2017; 15: 207. [PubMed][CrossRef]

10. Nasjonalt handlingsprogram med retningslinjer for diagnostikk, behandling og oppfølging av spiserørskreft. IS-2362. Oslo: Helsedirektoratet, 2015.

https://helsedirektoratet.no/Lists/Publikasjoner/Attachments/687/Spiser\%C3\%B8rkreft-handlingsprogr am-med-retningslinjer-IS-2362.pdf(10.9.2018).

11. Dindo D, Demartines N, Clavien PA. Classification of surgical complications: a new proposal with evaluation in a cohort of 6336 patients and results of a survey. Ann Surg 2004; 240: 205 - 13 .

[PubMed][CrossRef]

12. Ichikura T, Ogawa $\mathrm{T}$, Chochi K et al. Minimum number of lymph nodes that should be examined for the International Union Against Cancer/American Joint Committee on Cancer TNM classification of gastric carcinoma. World J Surg 2003; 27:330 - 3. [PubMed][CrossRef]

13. Jeong O, Ryu SY, Choi WY et al. Risk factors and learning curve associated with postoperative morbidity of laparoscopic total gastrectomy for gastric carcinoma. Ann Surg Oncol 2014; 21: 2994 3001. [PubMed][CrossRef]

14. Grøtting MS, Løberg EM, Johannessen HO et al. Reseksjon for oesophaguscancer - komplikasjoner 
og overlevelse. Tidsskr Nor Legeforen 2016; 136: 809-13. [PubMed][CrossRef]

15. Bringeland EA, Wasmuth HH, Johnsen G et al. Outcomes among patients treated for gastric adenocarcinoma during the last decade. J Surg Oncol 2013; 107: 752 - 7. [PubMed][CrossRef]

16. Gholami S, Janson L, Worhunsky DJ et al. Number of lymph nodes removed and survival after gastric cancer resection: An analysis from the US Gastric cancer collaborative. J Am Coll Surg 2015; 221: 291 - 9. [PubMed][CrossRef]

17. Pan Y, Chen K, Yu WH et al. Laparoscopic gastrectomy for elderly patients with gastric cancer: A systematic review with meta-analysis. Medicine (Baltimore) 2018; 97: eooo7. [PubMed][CrossRef]

18. Wang Y, Zhao X, Song Y et al. A systematic review and meta-analysis of robot-assisted versus laparoscopically assisted gastrectomy for gastric cancer. Medicine (Baltimore) 2017; 96: e8797. [PubMed][CrossRef]

19. Caruso S, Patriti A, Roviello F et al. Robot-assisted laparoscopic vs open gastrectomy for gastric cancer: Systematic review and meta-analysis. World J Clin Oncol 2017; 8: 273 - 84. [PubMed][CrossRef]

20. Paoletti X, Oba K, Burzykowski T et al. Benefit of adjuvant chemotherapy for resectable gastric cancer: a meta-analysis. JAMA 2010;303: 1729-37. [PubMed][CrossRef]

21. Bringeland EA, Wasmuth HH, Grønbech JE. Perioperative chemotherapy for resectable gastric cancer - what is the evidence? Scand J Gastroenterol 2017; 52: 647-53. [PubMed][CrossRef]

22. Jiang L, Yang KH, Chen Y et al. Systematic review and meta-analysis of the effectiveness and safety of extended lymphadenectomy in patients with resectable gastric cancer. Br J Surg 2014; 101: 595 - 604. [PubMed][CrossRef]

23. Seevaratnam R, Bocicariu A, Cardoso R et al. A meta-analysis of D1 versus D2 lymph node dissection. Gastric Cancer 2012; 15 (suppl 1): S6o - 9. [PubMed][CrossRef]

24. Hartgrink HH, van de Velde CJ, Putter H et al. Extended lymph node dissection for gastric cancer: who may benefit? Final results of the randomized Dutch gastric cancer group trial. J Clin Oncol 2004; 22: 2069 - 77. [PubMed][CrossRef]

25. Haverkamp L, Brenkman HJ, Seesing MF et al. Laparoscopic versus open gastrectomy for gastric cancer, a multicenter prospectively randomized controlled trial (LOGICA-trial). BMC Cancer 2015; 15: 556. [PubMed][CrossRef]

Publisert: 5. november 2018. Tidsskr Nor Legeforen. DOI: 10.4045/tidsskr.18.0404

Mottatt 7.5.2018, første revisjon innsendt 13.6.2018, godkjent 10.9.2018.

(C) Tidsskrift for Den norske legeforening 2020. Lastet ned fra tidsskriftet.no 